\title{
LA ESCALA ES UN PROBLEMA DIVERTIDO: LA POLUCIÓN DE LA ESCALA DE LAS OBRAS COMO UNO DE LOS SÍNTOMAS DEL COMPLEJO ARTE- ARQUITECTURA
}

\author{
Vicente Alemany Sánchez-Moscoso \\ Univ. Rey Juan Carlos de Madrid. Dpto. de Ciencias de la Educación, Lenguaje, Cultura y Artes, \\ Ciencias Histórico-Jurídicas y Humanísticas y Lenguas Modernas
}

\section{Resumen}

Desde los primeros años del siglo XXI los principales centros internacionales de difusión artística competían por contar con las más amplias salas de exposición diseñadas por los arquitectos más audaces. Los artistas debieron concebir sus proyectos adaptándolos a formatos cada vez mayores, esta ampliación les exigió reflexionar sobre qué relaciones de escala se podían establecer entre los espectadores y las obras dentro de las salas. La expansión global de estos centros de arte contemporáneo ha sido un fenómeno imparable, en el que el diseño arquitectónico de los edificios, y de todos los elementos que componen la experiencia del museo, ha tenido un papel fundamental. Se requiere una reflexión sobre el tipo de experiencia que ofrecen las obras en estos espectaculares espacios en los que se corre el peligro de que las piezas se conviertan en un elemento más del diseño. En la actualidad se están buscando otros espacios especializados en obras de gran escala.

Palabras clave: ARTE CONTEMPORÁNEO; ESCALA; MUSEO; ARQUITECTURA

\section{SCALE IS A FUNNY PROBLEM: THE POLLUTION OF THE SCALE OF THE WORKS AS ONE OF THE SYMTOMS OF THE ART-ARCHITECTURE COMPLEX}

\section{Abstract}

Since the early years of the 21st century, the main international centers of artistic diffusion competed for having the largest exhibition rooms designed by the most audacious architects. The artists had to conceive their projects adapting them to ever-larger formats. This expansion required them to reflect on what scale relationships could be established between the spectators and the works within the rooms. The global expansion of these contemporary art centers has been an unstoppable phenomenon, in which the architectural design of the buildings, and of all the elements that make up the museum experience, have played a fundamental role. A reflection is required on the type of experience offered by the works in these spectacular spaces in which they are in danger of becoming another element of design. At present other specialized spaces for large-scale works are being sought.

Keywords: CONTEMPORARY ART; SCALE; MUSEUM; ARCHITECTURE

\footnotetext{
Alemany Sánchez-Moscoso, Vicente. 2020. "La escala es un problema divertido: La polución de la escala de las obras como uno de los síntomas del complejo arte-arquitectura". AusArt 8 (2): 127-139. D0I: 10.1387 /ausart.22025
}

\section{AUSART}




\section{INTRODUCCIÓN}

La escala es un problema divertido. ¿Qué quieres decir? ¿Tamaño o escala? Te puedo decir que cuando las piezas se hicieron más grandes, y esa es una mejor definición para mi

(Serra 1994, 47)

Las proporciones son tan vitales como el agua y el aire que respiramos. (...) En la actualidad vivimos una polución de la escala tan grave como la de los recursos naturales.

(Virilio 2003, 110)

Los museos de arte contemporáneo son los espacios que mejor permiten valorar la complicidad en las relaciones entre arte y arquitectura de las últimas décadas, y las transformaciones que se han producido en las concepciones de la escala en las prácticas artísticas. La inauguración del Guggenheim de Bilbao en 1997 y de la Tate:Modern de Londres en 1999 (Alemany 2003, 123) señalaron dos hitos internacionales que han marcado el desarrollo en el ámbito de la creación y exhibición artística en el siglo XXI. En 1976 Brian O'Doherty publicó un artículo para la revista Artforum cuyo título podemos traducir como 'Apuntes sobre el espacio de las galerías'. Este artículo junto con El ojo y el espectador y El contexto como contenido fueron editados en 1986 en forma de un libro titulado Inside the white cube: The ideology of the gallery space. En sus descripciones O'Doherty sostiene que museos y galerías mantenían "algo de la santidad de una iglesia, de la solemnidad de una sala de justicia y de la mística de un laboratorio de investigación" ([1981] 2011, 20). En los últimos años del siglo $X X$ los dos escenarios en los que se desarrollarían los principales cambios en las relaciones entre las obras de arte y los espectadores fueron la Sala Grande del Museo Guggenheim de Bilbao y la Sala de las Turbinas de la Tate:Modern. Pronto se convirtieron en los espacios más significativos para comprender las nuevas relaciones de escala entre las obras de arte y las arquitecturas que las contienen. Si en 1977 en su célebre libro Pasajes de la escultura moderna Rosalind Krauss eligió las Puertas del infierno de Rodin como el umbral de inicio de su recorrido por la escultura vanguardista (Krauss [1977] 1996, 15), la Sala grande de las esculturas de Serra en Bilbao, y la Sala de las turbinas en Londres, configuraron el escenario más característico para describir las transformaciones de los museos de arte contemporáneo en el siglo XXI. 

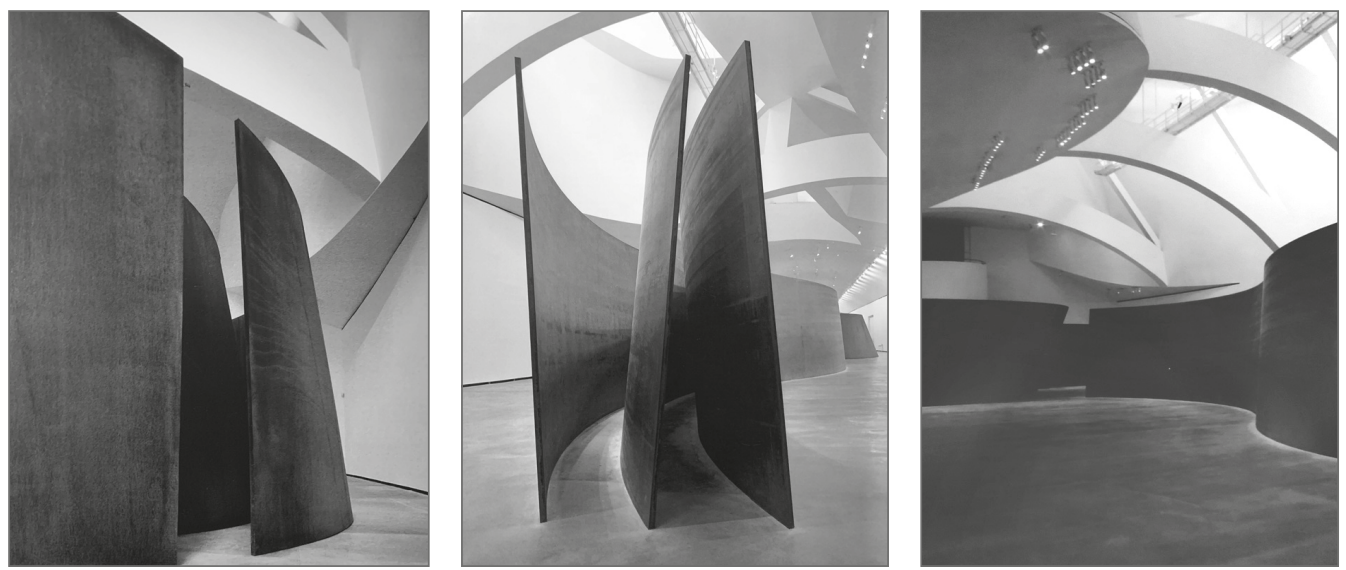

Richard Serra: Exposición Escultura (Izquierda), Exposición la Materia del tiempo (Centro y derecha). 1999 y 2005 (c) Richard Serra y Museo Guggenheim.

\section{ESTADO DE LA CUESTIÓN: MÁS ALLÁ DEL CUBO BLANCO}

Cuando el escultor norteamericano Richard Serra había completado por medio de maquetas de plomo las primeras series de Torsiones Elípticas de 1996, el creador californiano tuvo que esperar a que los mismos ingenieros que habían dado forma a la estructura del edificio de titanio de Frank O. Gehry desarrollasen en escala ampliada las colosales torsiones en planchas de acero cortén de dos pulgadas de grosor. En 1999 durante la exposición de Serra en Bilbao (Serra 1999) se produjo la más estrecha relación entre la arquitectura y la escultura contemporánea. Treinta años antes este creador californiano que había trabajado en una industria siderúrgica (Serra 2005, 178) realizó una célebre acción artística que consistió en arrojar plomo fundido en el encuentro de la pared y el suelo de la Galería de Leo Castelli. Estas propuestas que podríamos situar entre la práctica de la escultura y de la construcción arquitectónica se completarían de manera ejemplar en la exposición del Guggenheim de 1999. En esta muestra el espectador podía reconocer las mismas topologías en las planchas de metal de las esculturas de Serra y en los paneles curvados del edificio de Gehry.

Desde 2005 se puede observar el conjunto de piezas de Serra que forman la colección La materia del tiempo en el Guggenheim de Bilbao (Serra 2005) per- 
mitiéndonos apreciar esta simbiosis entre el contenido de la principal sala de este museo y su contenedor arquitectónico. Si recordamos el texto de O'Doherty, publicado en formato de libro tan sólo trece años antes, el cubo se proponía como paradigma ideológico de la arquitectura dedicada al arte, en tanto que forma de construcción estable, institucional y solemne. Por el contrario, la curvatura de los paramentos de Gehry y las planchas de acero cortén de Serra estaban manifestando el final del cubo y la ortogonalidad como modelo de la construcción contemporánea, tanto escultórica como arquitectónica. Este crítico ha llamado a esta tendencia actual como Against the White-cube [opuesta al cubo blanco] (O'Doherty 2007, 40). En el Guggenheim de Bilbao se desvanecería el hexaedro como forma ideal del museo, y el monolito como referencia típica de la escultura moderna (Greenberg [1958] 2014, 140), manifestándose las nuevas relaciones entre los espectadores y las obras que vienen caracterizando la arquitectura de museos en el Siglo XXI. La obstinada gravedad real de las planchas de Serra vencía cualquier idealismo formal para consolidar al postminimalismo como una Nueva Academia (Alemany 2009, 473).

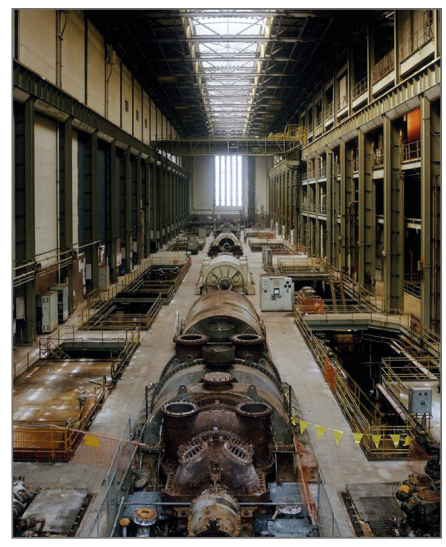

Marcus Leith: Sala de las turbinas durante su renovación, 1997. (c) Marcus Leith y Tate:Modern

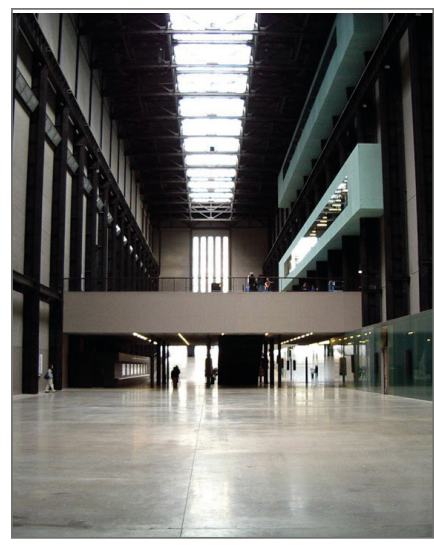

Herzog \& de Meuron: Sala de las turbinas. Tate:Modern. 1999. (C) Herzog \& de Meuron y Tate:Modern

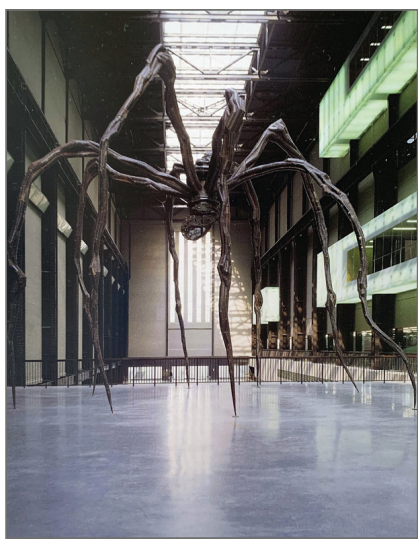

Louise Bourgeois: Mamá. 1999. @ Louise Bourgeois y Tate:Modern

En los últimos años de la década de los años noventa, mientras en Bilbao se completaba la construcción del Guggenheim, en Londres comenzaba la rehabilitación de una central eléctrica que había abastecido a la capital británica desde el final de la Segunda Guerra Mundial. El edificio original proyectado por Gil Gilbert Scott a finales de la década de 1940 fue rehabilitado por los arquitectos suizos Herzog y de Meuron tras ganar un concurso convocado en 1995. La operación consistió en conservar la estructura exterior del edificio y adaptar su interior a las necesidades de un museo de arte contemporáneo. La 
principal intervención exigió retirar las gigantescas turbinas que ocupaban la nave central del edificio y eliminar otros elementos menores que se distribuían en las dependencias laterales y superiores. De esta manera desaparecieron prácticamente todos los vestigios del origen industrial de la construcción de postguerra, mostrando tan sólo la estructura de hierro que sostiene la cubierta acristalada. Entre las vigas de acero roblonado tan sólo se mantuvo una grúa. Este espacio con más de 150 metros de longitud y 35 metros de altura, se consolidaría en pocos años como el espacio más destacado para la exhibición de arte contemporáneo del siglo XXI.

\section{DEFINICIÓN DE OBJETIVOS}

Con este artículo se pretende valorar qué tipo de aproximación entre el espectador y las obras han propiciado algunas de las arquitecturas de los museos de arte contemporáneo más célebres de las dos últimas décadas. Para ello se deberán distinguir entre las propuestas de artistas que generalmente trabajan en otras escalas menores de los proyectos de creadores de generaciones más jóvenes que han asumido esos espacios como los propios y más característicos de las últimas décadas. Podremos reconocer hasta qué punto la ampliación de las dimensiones de las salas de exhibición y de las piezas afectó a la experiencia que nos ofrecen las obras. Finalmente valoraremos cómo una generación completa de artistas se ha especializado en ofrecer obras y experiencias para estos museos típicos de la sociedad del espectáculo.
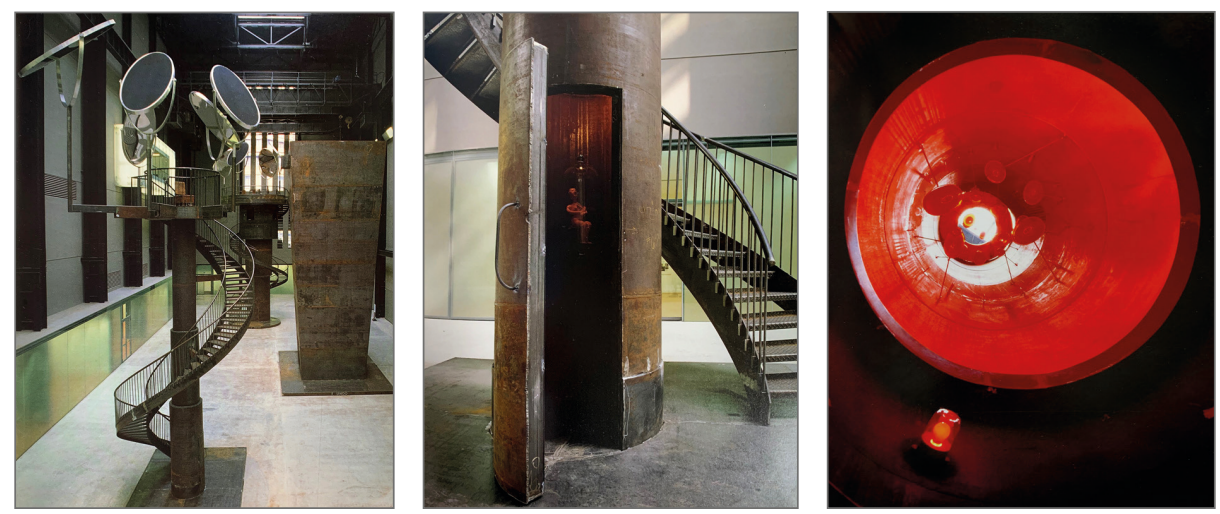

Louise Bourgeois: Hago, Hago (Detalle) y Deshago (Interior). 1998 y 1999

(C) Louise Bourgeois y Tate:Modern 


\section{APORTACIONES}

Richard Serra y Louise Bourgeois fueron los primeros artistas que se enfrentaron a estos nuevos espacios y tuvieron que adaptarse a las condiciones que estas salas imponían. Aunque ambos creadores trabajan con maquetas para proyectar sus esculturas, advertimos diferencias sustanciales entre las concepciones de tamaño y escala manejadas por Serra y Bourgeois, artista que inauguró la Sala de las Turbinas de la Tate. Serra ya manifestaba en los años sesenta su voluntad de que fuese la tecnología de construcción industrial la única que impusiese las limitaciones de escala de las obras (Serra 1994, 19). Por este motivo el tamaño de las planchas de sus obras de Bilbao se eligió por ser el máximo que podía manejar la maquinaria disponible en ese momento. Su voluntad siempre ha sido producir obras cuyo tamaño se confronte con las referencias del espectador, es decir que no se adapten a ninguna concepción relativa de la escala. Por el contrario, Bourgeois tiene una consideración subjetiva y existencial del espacio, y suele referirse a Gaston Bachelard y Albert Camus como sus referencias poéticas y filosóficas más apreciadas (Bourgeois 2001, 78-9). Cuando se desarrollaron sus piezas para la Tate:Modern a partir de modelos que tenían la apariencia de ser juguetes de apenas veinte centímetros de altura, no dudó en introducir variaciones sustanciales en esas estructuras que serían reinterpretadas en piezas de decenas de metros. Llenó los rincones con pequeñas cabinas, habitáculos y refugios. También convirtió las varillas centrales que conformaban los soportes de la escalera de caracol de las maquetas en estructuras telescópicas que parecían evocar el interior de un torrente sanguíneo. No sólo amplió las dimensiones de sus modelos, si no que hizo más compleja la obra ya que entiende que el tamaño de las piezas debe adecuarse a la intensidad de las emociones (Bourgeois 2001, 177-8).
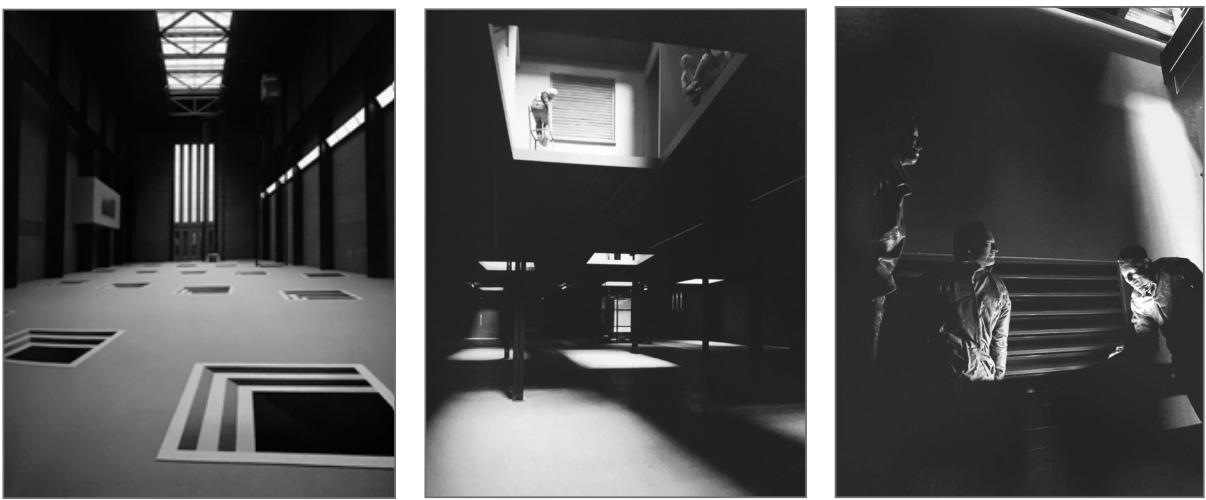

Juan Muñoz: Doble nudo. (Imagen general, vista inferior y detalle). 2000 (c) Estate of Juan Muñoz y Tate Modern 
Tras la exposición de Bourgeois en Londres se convocó a Juan Muñoz para que realizara su propuesta para la Sala de las turbinas. El artista madrileño presentó en 2000 su obra Doble nudo, una instalación con fuerte carácter escenográfico protagonizada por dos cabinas de ascensor vacías que subían y bajaban de manera sincronizada y en sentido inverso los 30 metros de altura de la sala. También se podían ver unas figuras que parecían habitar unos espacios un tanto siniestros que se escondían en un entresuelo diseñado por Muñoz, sobre el que se extendía un pavimento con trampantojos (Muñoz 2001). La pieza que le sirvió de antecedente era una pequeña maqueta de un ascensor que subía y bajaba escondido tras un tabique en su instalación Un lugar llamado extranjero de 1996 presentada en Nueva York en el museo Dia:Chelsea en 1996, también los trampantojos -y otros elementos escenográficos- han sido comunes en toda su trayectoria. La concepción de escala en los proyectos de Muñoz es similar a la de Bourgeois ya que la ampliación de aquel ascensor no supuso tan sólo un incremento de tamaño, como el que se produce en las piezas de Serra, sino que exigió una revisión de sus referencias para multiplicar las posibilidades de interpretación simbólica de la obra. Los espacios ocultos del entresuelo se convertían en pequeños escenarios, de fuerte carácter industrial, con ciertos elementos comunes a las Celdas de Bourgeois.

A la propuesta de Muñoz en la Sala de Las Turbinas le seguiría la obra de Anish Kapoor titulada Marsias de 2001. Esta gigantesca escultura estaba dedicada a representar el despellejamiento de Marsias descrito en las Metamorfosis de Ovidio que fue pintado por Tiziano en 1575, y se mostraba en la National Gallery de Londres coincidiendo con la exhibición de la instalación de Kapoor. Una reproducción de este cuadro fue la referencia inicial de todos los dibujos realizados durante los meses de preparación de esta obra. Este material gráfico junto con multitud de maquetas fueron documentadas en la amplia monografía que publicó la Tate Modern. En todos los dibujos y modelos a escala aparecen pequeñas figuras, que señalan el lugar y la medida de espectador. Kapoor en su entrevista con Donna de Salvo (2002) insiste en recordar "estoy realmente interesado en lo íntimo. El arte es bueno enfrentándonos a relaciones íntimas. Un problema de la Sala de las Turbinas era encontrar intimidad entre el espectador y la obra". El escultor británico de origen indio desde comienzo de su carrera insistía en que sus obras tienen que ser espacios de contemplación, de meditación, describiéndolos como pequeños templos. En su entrevista con Marjorie Allthorpe-Guyton (1990), ya señalaba:

Un aspecto esencial de mi trabajo es que la escala esté siempre en relación con el cuerpo. (...) La sensación de lugar se ha 
instalado al interior de las obras: Lo que hizo necesario al cambiar escala. El espacio interno es un espacio mental y corporal. Una capilla para una persona.

(Kapoor 1990, 40)
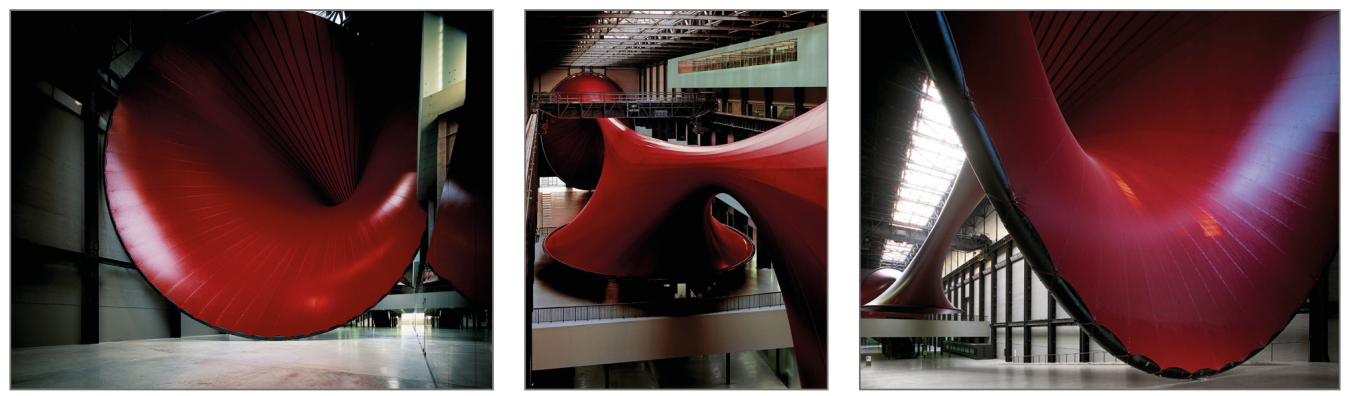

Anish Kapoor: Marsyas. 2002. @ Anish Kapoor y Tate:Modern

\section{DISCUSIÓN}

Las galerías se construyen con leyes tan rigurosas como las que se aplicaban en la construcción de una iglesia medieval. El mundo exterior no debe penetrar en ellas y, por eso mismo, las ventanas suelen estar cegadas. Las paredes están pintadas de blanco, la luz viene del techo

(O’Doherty [1981] 2011, 21)

En sus artículos publicados originalmente entre 1976 y 1981, Brian O'Doherty señalaba la afinidad entre los espacios de exhibición del arte moderno y las catedrales. Aunque esta descripción puede servirnos para resumir las características físicas de la Sala de las turbinas, o la sala Grande del Guggenheim de Bilbao, sin embargo, en su interior será difícil que tengamos una experiencia de recogimiento, no se favorecerá que nos formemos un juicio sobre las obras, ni se genera un ambiente de investigación. Cuando O'Doherty empleaba palabras como meditación, solemnidad o misticismo para describir el ambiente de las galerías de arte en las décadas de 1970 y 1980 no podía imaginar que, aunque los elementos básicos del diseño de estos espacios se mantuviesen, no obstante, la ampliación de escala produciría una transformación radical que modificaría el tipo de relación que los espectadores podían establecer con las obras. El incremento sustancial del tamaño del Museo Guggenheim de Bilbao 
y de la Tate:Modern de Londres, y su éxito como oferta cultural, provocaron que se produjese un acceso creciente de público. En el caso específico de la Sala de las turbinas la afluencia de visitantes creció aún más porque se trataba de un espacio de libre acceso. Pocos años después se había convertido en un lugar de encuentro social en el que se reunían londinenses y turistas, aunque no tuvieran previsto acceder a las colecciones de arte de las plantas superiores.
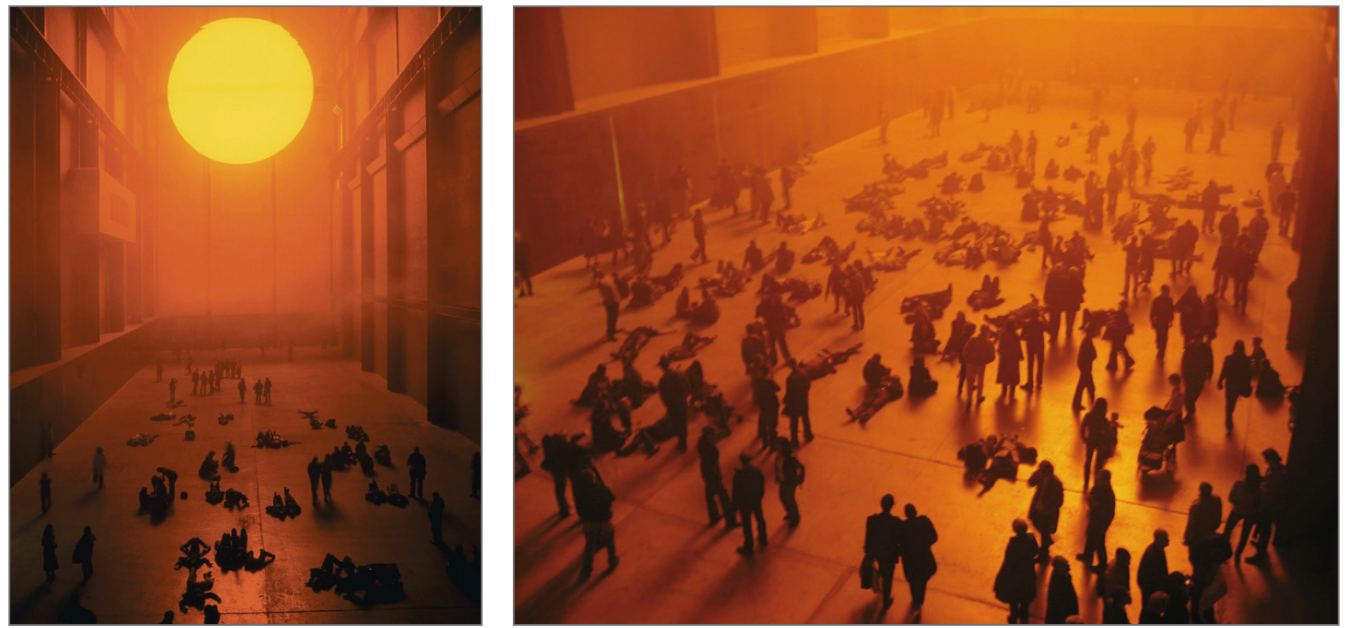

Olafur Eliasson: The Weather Project. 2003 @ Olafur Eliasson y Tate:Modern

Podemos describir las obras que Olafur Eliasson y Carsten Höller proyectaron en la Sala de las Turbinas de Londres para comprobar como muy pocos años después de su inauguración las relaciones que podían establecer los espectadores con las obras habían cambiado radicalmente. El arquitecto de origen danés Olafur Eliasson presentó en 2003 su propuesta The Weather Project [El proyecto del clima] que consistía en construir un sol simulado por medio de estufas eléctricas. También cubrió el techo de la Sala de las Turbinas con paneles de espejo de manera que en el interior de la nave se producía la imagen de una esfera luminosa (Eliasson 2003). Los visitantes se tumbaban en el suelo para sentir la radiación halógena que calentaba sus cuerpos en el frio y húmedo invierno londinense. Poco después moviendo las piernas y algún brazo intentaban localizar la imagen de sus cuerpos reflejados en el techo de la Sala de las turbinas y con sus teléfonos móviles fotografiaban esas imágenes. La propuesta de Carsten Höller de 2006 tuvo el mismo carácter lúdico, participativo y desenfadado de la de Olafur Eliasson. La intervención de este artista de origen alemán nacido en Bruselas consistió en montar hasta cinco 
rampas de toboganes de acero inoxidable. Estos conductos espirales cerrados con una pantalla de metacrilato permitían a los espectadores que subían a las plantas superiores bajar deslizándose a velocidad moderada. Al final del recorrido los espectadores se levantaban divertidos y algo mareados por los giros que habían dado a lo largo del descenso. Este tipo de obras que se han hecho cada vez más frecuentes y características en estas instituciones requieren una reflexión sobre el sentido de nuestro interés hacia las obras de arte. ¿Qué tipo de experiencia queremos extraer del arte contemporáneo? ¿Queremos hacernos un selfie en el que aparezcamos tumbados en el suelo jugando con nuestro reflejo en el techo? ¿Queremos que las obras sean algo similar a un columpio y los museos parques recreativos para adultos? ¿Deseamos obtener un cierto disfrute y mareo que los artistas explican como una invitación a participar en los museos de otra manera? (Höller 2006).
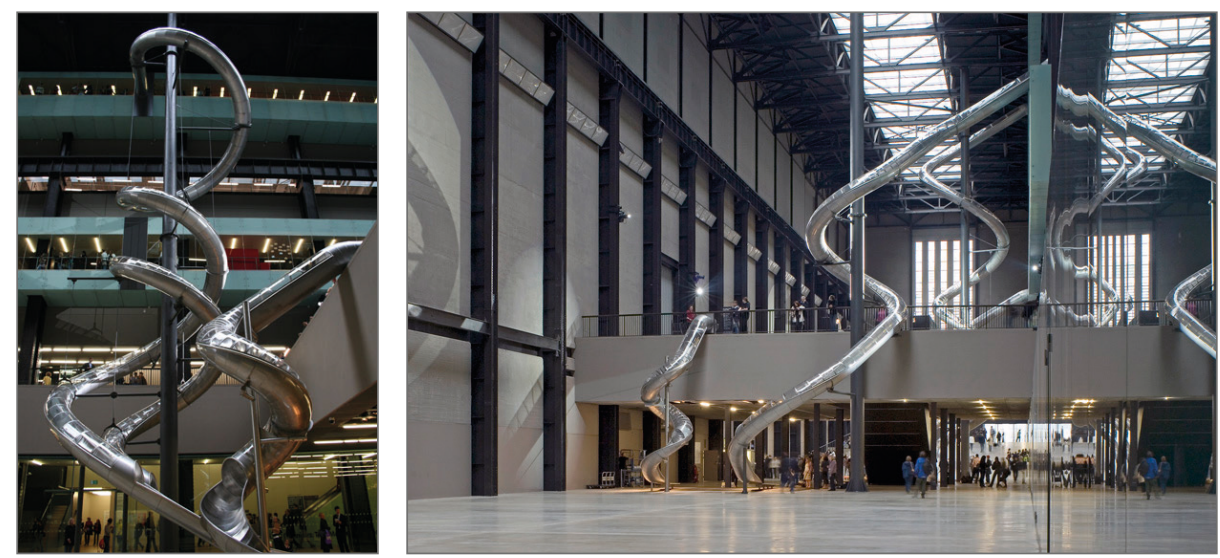

Carsten Höller: Site Test. 2006 @ Carsten Höller y Tate:Modern

\section{CONCLUSIONES}

Hal Foster describió en su libro Diseño y delito (2004) cómo la inflación de los fenómenos asociados al diseño y al consumo en los entornos de los museos estaba produciendo una reacción inversa de decrecimiento del interés estético de las obras propuestas. Recurría al célebre texto de Adolf Loos Ornamento $y$ delito de 1908 en el que el arquitecto vienés defendía que tras la abundancia de ornamento del secesionismo se escondía la culpa de una aristocracia indolente, retrograda y corrupta. En su libro El complejo arte-arquitectura ha analizado los fenómenos de expansión del diseño en los museos de arte contemporáneo con términos que evocan las descripciones de los proyectos urba- 
nísticos, los entramados financieros y las patologías médicas (Foster 2013, 15). Sus estudios analizan cómo este masivo sistema económico y tecnológico que implica disciplinas como el diseño, el arte y la arquitectura paradójicamente produce un debilitamiento de la capacidad crítica de los espectadores. La inflación de los recursos de diseño, y la ampliación desmedida de la escala, limitan la capacidad de provocar una experiencia de lo que las piezas nos ofrecen por si mismas. Esta polución dificulta establecer un juicio estético, ya que imposibilita una aproximación atenta y reflexiva, una cierta intimidad entre el espectador y la obra.

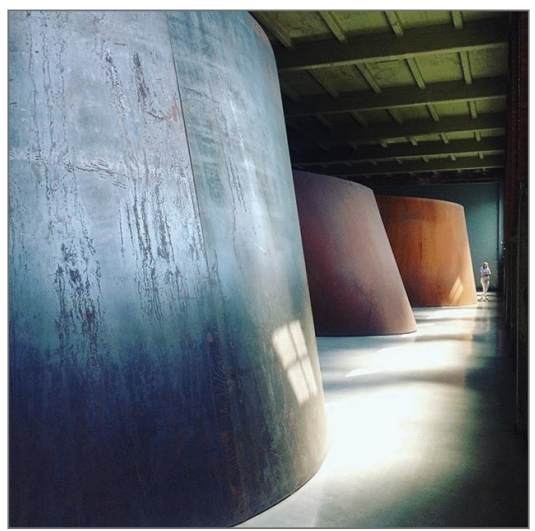

Richard Serra: Torsiones elípticas en el Dia:Beacon. 1996-2002 @ Richard Serra y Dia:Foundation

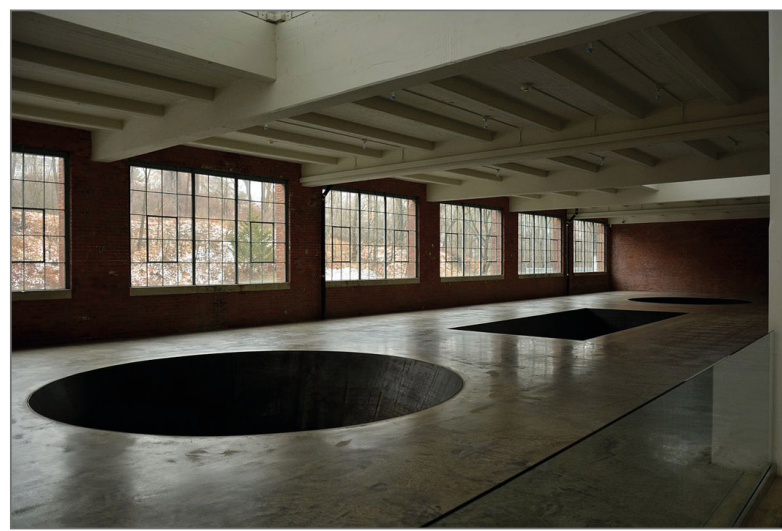

Michael Heizer: Norte, Este, Sur y Oeste. 1967-2002 @ Micahel Heize y Dia:Foundation

En este proceso global de retroceso de la calidad de las experiencias estéticas que podemos tener en los museos en la actualidad, se hace especialmente importante reconocer el esfuerzo que realizan algunas instituciones para mostrar las obras de arte en entornos que no caigan en la polución de las proporciones y la falta de intimidad ante las obras. Por este motivo comisarios de exposiciones, conservadores de museos, arquitectos, artistas y otros especialistas en arte actual, se reunieron en Verbier, Valais, Suiza en 2017 en una cumbre internacional para reflexionar acerca de la escala en los museos en el siglo XXI. El título de la primera edición del Verbier Art Summit que podemos traducir como ' $i E l$ tamaño importa! (De)crecimiento del museo de arte del siglo XXI' manifiesta el interés de todos los sectores implicados en las consecuencias de la escala en la percepción del arte actual (Beech et al. 2017). Uno de los espacios que los especialistas consideran como ejemplo de equilibro entre el tamaño de obras, la escala del museo y la calidad de las experiencias que se provocan es el Dia:Beacon. El artista Robert Irwin fue el encargado de coordinar el diseño de este centro instalado en una fábrica rehabilitada 
en el interior del estado de Nueva York (Cooke \& Govan 2003). También en Europa contamos con algunas fundaciones artísticas relativamente alejadas de la expansión de los grandes complejos de arte y arquitectura que hemos estudiado, y que sin embargo están realizando una gran labor en la exhibición de obras de gran formato, sin caer en los errores que hemos descrito. Es el caso del Pirelli Hangar Bicoca cerca de Milán, o de las obras que la Fundación Sorigué muestra en el centro Planta en Balaguer, cerca de Lérida. En sus instalaciones se exhibe la reconstrucción de Doble nudo de Juan Muñoz, y se mantienen expuestas obras de artistas como Bill Viola o Anselm Kiefer en las condiciones diseñadas por los propios autores.

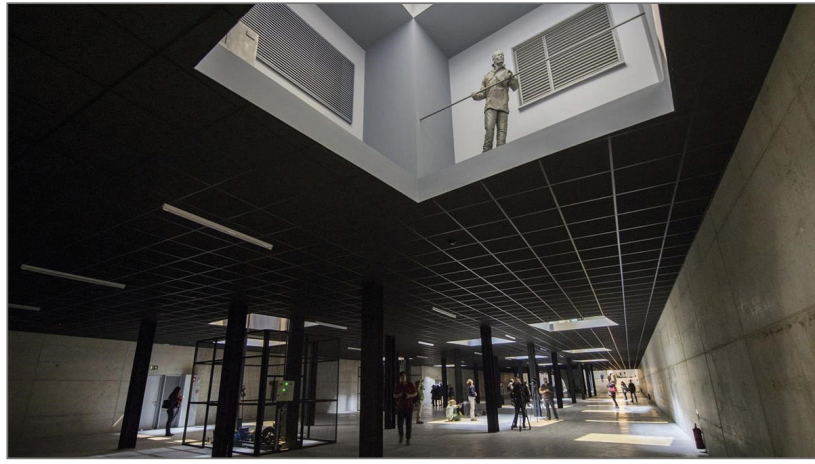

Juan Muñoz: Detalle de Doble nudo. 2000-2017 @ Ramón Gabriel, Juan Muñoz y Fundación Sorigué

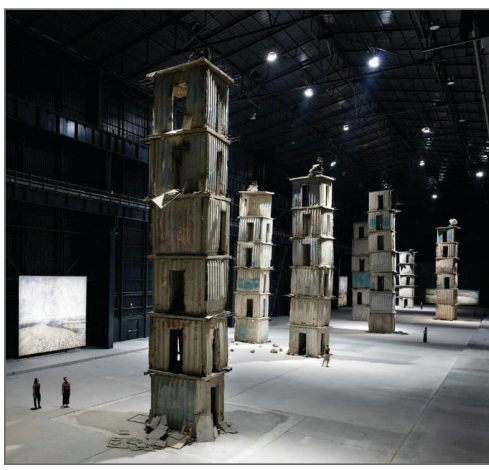

Anselm Kiefer: Siete palacios celestes. 2004-2015 @ Anselm Kiefer y Pirelli Hangar Bicoca

\section{Referencias bibliográficas}

Alemany Sánchez-Moscoso, Vicente. 2003. Arte del siglo XX: Apuntes al principio de un siglo. Madrid: Dykinson

Alemany Sánchez-Moscoso, Vicente. 2008. "La antropometría en el postminimalismo: Estudio sobre las relaciones métricas entre el espectador y las obras en la escultura norteamericana heredera del minimalismo de las décadas de 1960 y 1970". Madrid: Tesis Doctoral Universidad Complutense

Beech, Dave et al. 2017. Size matters! (De)growth of the 21st Century art museum. Verbier Art Summit, January 2016. Berlin: Köning

Bourgeois, Louise. 2001. Destrucción del padre, reconstrucción del padre : Escritos y entrevistas, 1923-1997. Traducción Rafael Jackson \& Pedro Navarro. Madrid: Síntesis

Cooke, Lynne \& Michael Govan. 2003. Dia: Beacon. New York: Dia Art Foundation

Eliasson, Olafur. 2004. The Weather project. London: Tate Gallery

Foster, Hal. 2004. Diseño y delito: Y otras diatribas. Traducción de Alfredo Brotons Muñoz.

Barcelona: Akal 
Foster, Hal. 2015. El complejo arte-arquitectura. Traducción de José Adrián Vitier. Barcelona: Destino

Greenberg, Clement. (1958) 2019: "La nueva escultura”. En Arte y cultura: Ensayos críticos, traducción de Justo G. Beramendi \& Daniel Gamper. Barcelona: Paidós

Höller, Carsten. 2006. Site test. London: Tate Gallery

Kapoor, Anish. 1990. "Interview with Anish Kapoor". By Marjorie Allthorpe-Guyton. En Anish Kapoor: British Pavilion, XLIV Venice Biennale, May-September 1990. London: British Council Visual Arts Department

Kapoor, Anish. 2002. "Interview”. By Donna De Salvo. En Marsyas, texts, Donna De Salvo \& Cecil Balmond, 60-4. London: Tate Gallery

Krauss, Rosalind E. (1977) 1996: Pasajes de la escultura moderna. Traducción, Alfredo Brotons Muñoz. Madrid: Akal

Muñoz, Juan. 2001. Double bind at Tate Modern. Text by Susan May. London: Tate Gallery

O’Doherty, Brian. (1981) 2011. Dentro del cubo blanco: La ideología del espacio expositivo. Murcia: Cendeac. Pub. orig. en: Artforum, 1976-81

O’Doherty, Brian. 2007. Studio and cube. New York: Princeton

Serra, Richard. 1994. "Interview by Liza Bear". En Writings, interviews, 51-60. Chicago IL: Chicago University

Serra, Richard. 1999. Richard Serra: Escultura 1985-1999. Organizada por Richard Koshalek \& Julia Brown. Bilbao: Museo Guggenheim Bilbao

Serra, Richard. 2005. Richard Serra: La materia del tiempo. Textos de Hal Foster et al. Museo Guggenheim Bilbao

Virilio, Paul. 2003. Unknown quantity. London: Thames \& Hudson 